\title{
Housekeeping Standard Practices of Resorts in Bohol, Philippines
}

\author{
Jesszon B. Cano, MBA-HRM \\ Hospitality Management \\ Bohol Island State University \\ Philippines \\ Grayfield T. Bajao, DM-HRM \\ Jonathan O. Etcuban, PhD \\ Graduate School \\ University of Cebu \\ Philippines
}

\begin{abstract}
Housekeeping standard practices are vital to the hospitality industry because they guide the performance of the room attendants. This study assessed the satisfaction of the guests on housekeeping standard practices of the room attendants. Fifty guests took part in this study. The instruments made up of three parts. Part 1 pertains to the respondents' profile, part 2 contains items on determining the level of satisfaction of the guests, and part 3 pertains to the common problems encountered by the guests. The gathered data were treated statistically using frequency, simple percentage, weighted mean, and Spearman's rho. Guests had expressed their satisfaction with the overall service they received. However, resort guests also encountered some problems while staying in the resort. The information on service quality gaps could help resort managers to diagnose where performance improvement can best be targeted. Establishments need a relatively stable labor force to allow internalization of service standards.
\end{abstract}

Keywords: Business and management, hospitality, standard practices, descriptive method, Philippines

\section{Introduction}

Housekeeping standard practices are vital to the hospitality industry because they promote and guide the performance of the room attendants. It is an evaluation tool for the management and employees to ensure efficiency and proficiency during their work. Housekeeping standard practices are also used to provide a framework for developing quality competency checklists or proficiency evaluations for a specific housekeeping manager or supervisor for the development of their attendants. These norms may be used as a comparison tool to evaluate the housekeeping staff's performance if the housekeeping manager or supervisor suspects poor performance, unsafe work habits and nonadherence to the organizational policies and widely- accepted housekeeping guidelines. The findings will be the basis for corrective action to avoid deviation between the housekeeping standard practices and the actual performance of the room attendants (Davis, 2014).

The housekeeping department is one of the departments in the hotel organization whose primary responsibility is to keep the hotel area clean and tidy. The success and credibility of the hotels' business depend mainly on their quality standard practices and competent professionals who performed the tasks as mentioned above. One of the motivating factors to have top quality service is dedication, passion, and commitment among its housekeeping staff. The team succeeds in building and maintaining the right image and reputation of the hotel by providing excellent and quality service through standard practices (Phillips, 2017).

There are gaps incompetence of the resort personnel in the housekeeping department of the resorts in Anda, Bohol since most of these establishments are modest at the same time, the amenities and services offered are limited. Additionally, a well-trained staff must be retained to ensure consistency and reliability of one's work; and productivity of performance towards the goals of the business industry. Moreover, variance training and seminars can enhance individual to improve their skills into the exceptional quality of service continuously.

The room attendant is considered as the ambassador of the housekeeping department, since he/she is responsible for providing hospitality, ensuring guests' safety and comfort during their stay in the resort. Thus, resort owners and managers are putting more and more effort into monitoring and maintaining the high level of satisfaction of their guest. 
Because of expanding worldwide market rivalry, numerous inn organizations are confronting difficulties in holding visitors. Some market researchers have proven that most hotel companies in Europe and the U.S. will lose half their guest throughout five years because they are not satisfied on the services rendered by the room attendants (Carev, 2008). Also, some of the resorts in the Philippines provides poor quality in providing housekeeping services to the resort guests. Low-quality service leads to low satisfaction, discouraging guests from returning (Pesonen, 2015).

Furthermore, the researcher observed that resorts in Anda, Bohol are facing challenges in retaining resort guests because they are significantly affected by the quality of services rendered by the resort attendants due to the absence of proper training and higher educational background.

As hospitality management instructors, the researchers desired to distinguish a practical solution to the gaps incompetence of the resort personnel in the housekeeping department of the resorts in Anda, Bohol. Moreover, the researchers aspired to employ practical applications to solve any identified problems and to get more profound insights about responding to guests' satisfaction when it comes to standard housekeeping practices of room attendants. This is to look forward to more beneficial outcomes and to ensure better information which will eventually help resort management to plan for the future. Furthermore, the researchers firmly believe that providing exceptional housekeeping services is a significant factor to achieve guest satisfaction at a peak level.

\section{Framework}

This examination is tied down on the Theory of Customer Service by Dorling (2017), places that client administration depends on distinguishing and fulfilling your clients' needs and surpassing their desires. An organization must be focused on conveying reliably elevated requirements of administration to pick up and hold client reliability. Everybody in the association must be tuned into what the client needs. Making a client administration culture inside an organization can help construct achievement. Consumer loyalty and dependability are inseparably connected to the nature of client administration and, eventually, to the organization's productivity by giving thorough preparing programs that make them specialists in their field; underlining how giving brilliant client administration is the foundation of your business; guaranteeing the bleeding edge client administration group is affable, benevolent and proficient; engaging workers to settle on choices that lead to consumer loyalty; and remunerating extraordinary representative execution with acknowledgment in the organization bulletin, celebratory meals, prizes and different advantages.

In the late 1970s, Dr. Nariaki Kano of Tokyo Rika University came out with an exciting and practical model for understanding customer satisfaction known as the Kano Model. The Kano show is a lot of thoughts for arranging another item, administration or procedure. It records all the potential client needs that the item, administration or procedure ought to maybe endeavor to fulfill. This hypothesis was gone for a superior comprehension of how clients advance, assess and see quality characteristics and concentrated on the properties considered increasingly basic by clients so as to improve them. Kano demonstrates clarifies how the distinctions that different the degree called adequate by that of superb while thinking about the consumer loyalty. The hypothesis of excellent quality thinks about that quality characteristics are dynamic, which implies that after some time, an element may change from attractive to unacceptable. Concentrates in the writing drove us to the end that the use of Kano Model is basic for planning items and administrations, assembling or conveying of administrations, dissecting the attributes of the administration, deciding consumer loyalty, ceaseless improvement of value. This model expresses that fulfillment and disappointment are two free ideas in the psyche of the shopper and ought to be considered independently. Inferred that the connection between the execution of a need and fulfillment or disappointment as experience isn't really direct. The Kano Model acquires an alternate point of view request to dissect the potential outcomes of improving the nature of items and administrations, since it considers the nonlinear connection among execution and fulfillment (Bitran and Pedrosa, 1998).

In the Dissonance Theory of Yuksel (2008), an individual who anticipated a high-esteem item or administration and got a low-esteem item or administration would perceive the dissimilarity and experience psychological discord. That is, the disconfirmed desires make a condition of cacophony or mental uneasiness. As per this hypothesis, the presence of discord produces weights for its decrease, which could be accomplished by altering the apparent divergence. This hypothesis holds that post-presentation appraisals are fundamentally an element of the desire level on the grounds that the errand of perceiving disconfirmation is accepted to be mentally awkward. Subsequently, shoppers are set to perceptually mutilate desire discrepant execution to match with their past desire level. For example, if a dissimilarity exists between item/administration desires and item/administration execution, purchasers may have a mental pressure and endeavor to decrease it by changing their view of the item. 
In addition, Batinić (2015) noticed that lodging housekeeping division is spoken to in each authoritative structure of the inn, and its size and structure relies upon the sort and size of the inn, first offer, and substance, class of the inn, the dimension of use and the term of the inn business. The essential job of inn housekeeping is cleaning and support of lodging units and rooms, and the determination of the head inn servant, who will effectively lead the housekeeping division is noteworthy for a fruitful business, acknowledgment, and notoriety of the inn. Notwithstanding higher or college instruction and language abilities, the head servant must have the administration aptitudes identified with arranging, sorting out, driving and controlling, just as general and expert learning of the brain research of work and cleanliness. The head lodging maid, as an inn chief, composes, coordinates and controls crafted by inn housekeeping. It is in charge of the precision of the inhabitance rate report, readiness of rooms and other lodging units, to accomplish the most abnormal amount of nature of inn administrations, preparing of representatives, for the use of norms and constant utilization of the business arrangement of the inn.

Pesonen (2015) included that housekeeping is as yet utilized in family units particularly individuals who are rich and renowned yet is presently better known in lodgings and resorts far and wide. Maids have a wide cluster of errands they need to deal with in full time work. The servant is a standout amongst the most basic representatives in a lodging. A few divisions believe that the housekeeping office isn't deserving of referencing yet without the servants, the lodging would not have anything to sell. The work that they do is variable and changes day by day. The outlines reveal to them what number of rooms they will be finished that day, what floor in the lodging they will take a shot at and regardless of whether they are leaving rooms or remain over rooms.

Pongsiri et al. (2013) contemplated that conveying quality administration is one of the critical difficulties confronting neighborliness workers. This test will be a basic condition for accomplishment in the rising, definitely aggressive, worldwide neighborliness advertise. Administration quality in a particular zone of housekeeping was caught as housekeeping HR overseeing and creating. Travel and Tourism Competitiveness Report (2017) claims that poor language capacity, relational abilities, absence of property upkeep, problematic administration, powerless framework, and poor sanitation are considered as low quality of administration contrasting with direct partners in Asia such Singapore and Malaysia. Offering reliable and magnificent administrations won't help just Thailand's lodgings to satisfy the worldwide guideline yet additionally expanding its global intensity.

China is additionally tested to finish the ASEAN fragment as a similar market with rivals in Asia-Pacific districts, which exceptionally regarded on the complex inn industry with a comparative item yet better in administrations. The inns have likewise confronted the circumstance of lacking qualified worker that could give administration on worldwide administration standard. The housekeeping staff in Thailand are for the most part not accomplished and had a place with the old age of ladies. This influenced the picture of the housekeeping work which moved toward becoming lower levelled, hard and poor. The new age keeps away from the region of housekeeping that influences the absence of talented servant assets (Tsang \&Qu, 2000).

Knežević et al. (2017) explained that quality of hotel much more demanding and challenging than measuring the quality of physically tangible products because, in addition to material components in the hotel, great importance is attached to the process of service delivery in which employees play a crucial role. In order to accurately determine the quality of services in the hotel industry, it is necessary to measure the level of the hotel guests' satisfaction with the provided service. It should be noted quality the guests are active participants, in the creation and delivery as much as in the overall quality of service.

Živković (2011) believes that the main objectives in all measurements of the customers' satisfaction with the provided services or products are monitoring the guests' quality of products and services, choosing a good feedback system related to the experiences of consumers. Determining the hotel guests' satisfaction with the provided services is a crucial activity for management so that the quality of the service process. Customers' satisfaction can be direct and indirect measurements methods. The aim of the presented the attitudes of the guests and to measure their satisfaction with the user provided services. By obtaining their ratings, it is possible to identify the shortcomings whose removal means gaining a competitive advantage.

Batinić (2015) testified that hotel services are composed of some processes or procedures to be managed and to be continuously maintained and improved in order to eliminate defects and faults in order to achieve greater consumer satisfaction. By elaborating the service process, it helps employees to understand better how to provide top quality hotel services. In hotels, the focus of quality is transferred to service providers, and the quality of services depends on the knowledge, skills, experience, appearance, behavior and other characteristics of employees. Educated, professionally trained, highly motivated and loyal employees create and maintain the quality that affects the satisfaction of our guests (Kimanuka, 2014). 
Hodson (2017) verified that the individuals who need to travel consistently and remain in a scope of various inns and motels the nation over would have encountered a few issues with various lodgings, and whether you are in the United States or on the opposite side of the world, huge numbers of the issues that visitors experience are the equivalent. A standout amongst the most widely recognized issues that individuals experience is the point at which the neighbors in contiguous rooms are boisterous, and this can go from overwhelming wheezing through to the individuals who are up late around evening time or coming back from a night out. Sometimes, lodgings may need to remove rooms from administration if there is a specialized issue, while in different circumstances they may have over-booked their rooms.

For the individuals who appear and there is no room present for them, at that point they might be restricted regarding what they can do past grumbling, yet it is without a doubt fundamental to get the full subtleties from the lodging staff. Take this up with the administrator of the lodging, and clarify the circumstance and how you were managed. On the off chance that you don't have any achievement, at that point in any event you can leave a survey on movement audit sites cautioning others about the issues with that specific inn.

Carev (2008) demonstrated that for the lodging business, the idea of conveying quality administration for guaranteeing visitors fulfillment to accomplish visitors' dedication and resulting rehash business has dependably been a typical presumption with respect to numerous scholars and experts. Brilliant administration urges for fulfilled visitors to return for rehash visits to a similar inn, and on the other hand, regardless of whether low-quality administration prompts low fulfillment, demoralizing visitors from returning. This supposition is a generally held conviction, gave the inn offers quality support of increase visitor fulfillment and, consequently visitor reliability. Because of expanding worldwide market rivalry, numerous lodging organizations are confronting difficulties in holding clients. By raising fulfillment or quality guidelines, organizations bit by bit raise visitors' desire level, which at that point makes it progressively troublesome and all the more exorbitant to satisfy them. Clutching a returning visitor is fundamental to a lodging in light of the fact that after some time they diminish the expense of administration. A returning visitor knows the item; requires less data; buys more administrations; pay more expensive rates for those administrations; and readily offers informal proposals to other people.

In an examination led by Fouad et al. (2013) on the housekeeping execution and visitor fulfillment in resort inns found that the inns are confronting the circumstance of lacking qualified workers because of the inadequate preparing which is come about because of the high turnover rate, in this way couldn't give administration on global administration standard. The new age maintains a strategic distance from the zone of housekeeping, influencing absence of gifted maid assets. In any case, the housekeeping isn't customarily considered by the lodging director as a cutting edge administration office. Consequently, administration preparing offered to housekeeping staff is insignificant in examination with that accommodated gathering and eatery staff.

By and by, few research considers have engaged and recognized which components of housekeeping administration quality that altogether impact consumer loyalty in this bureau of the lodging. Creating friendliness administration is fundamentally vital to an association's act, visitor fulfillment, notoriety, devotion and at last benefit. The business performance depends on the summation of individual performances. Better service should result in a successful organization (Smith, 2017).

Housekeeping standard practices, therefore, helps the room attendants in developing and putting into practice the standard operating procedure which increases the effectiveness and efficiency of the housekeeping services. It describes the competent level of performance in each phase of the working process. They reflect a desired and achievable level of performance against which an employee's actual performance can be compared. The primary purpose of housekeeping standard practices is to direct and maintain efficiency and quality of competent practice. Thus, room attendants' low performance will negatively impact the quality of service and the desired competitiveness of an establishment. The information on service quality gaps could help resort managers to diagnose where performance improvement can best be targeted.

\section{Objectives of the Study}

This study assessed the satisfaction of the guests on housekeeping standard practices of the room attendants in selected resorts in Anda, Bohol. Specifically, it sought to answer the: 1) Profile of the respondents; 2) Level of satisfaction of the guests pertaining to the housekeeping standard practices; 3) Problems encountered by the guests in relation to housekeeping standard practices of the resorts; and 4) Significant relationship between the respondents' profile and the respondents' perception of the problems they encountered in relation to housekeeping standard practices of the resorts. 


\section{Methodology}

This study utilized a descriptive-correlational method of research using the researcher made a tool to determine the level of satisfaction of the guests on housekeeping services of selected resorts in Anda, Bohol.

This study was conducted in Anda, Bohol where it is situated in the eastern coast of the island, roughly 110 kilometer or three-hours ride from Tagbilaran City in which many neighboring resorts are located like Old Castle, Flower Beach Resort, Anda de Boracay White Sand Beach Resort, East Coast White Sand Resort \& Recreational Center, and Anda Global Beach Resort. Fifty resort guests in five selected resorts in Anda, Bohol took part in this study.

This study used researcher made instrument patterned from the training standards of the Technical Education and Skills Development Authority (TESDA). The said instruments made up of three parts. Part 1 pertains to the respondents' profile, part 2 contains items on determining the level of satisfaction of the guests in the housekeeping standard practices of the resorts, and part 3 pertains to the common problems encountered by the resort's guest about the housekeeping services.

After gathering data from resort guests and the room attendants, these were processed, analyzed and interpreted. The gathered data were treated statistically using frequency, simple percentage, weighted mean, and Spearman's rho.

\section{Results and Discussions}

Table 1: Profile of the Respondents

\begin{tabular}{lcr}
\multicolumn{3}{c}{$(\mathbf{n = 5 0 )}$} \\
\hline Profile & Frequency & Percentage \\
\hline I. Age & 4 & 8.00 \\
$18-20$ & 8 & 16.00 \\
$21-30$ & 16 & 32.00 \\
$31-40$ & 14 & 28.00 \\
$41-50$ & 2 & 4.00 \\
$51-60$ & 6 & 12.00 \\
Above 60 & & \\
II. Gender & 30 & 60.00 \\
Male & 20 & 40.00 \\
Female & & \\
III. Civil Status & 18 & 36.00 \\
Single & 30 & 60.00 \\
Married & 2 & 4.00 \\
$\quad$ Separated & & \\
IV. Continent of & & \\
Origin & & \\
$\quad$ Asia & 30 & 28.00 \\
$\quad$ Europe & 14 & 4.00 \\
Africa & 2 & 4.00 \\
$\quad$ North America & 2 & 4.00 \\
$\quad$ Australia & 2 &
\end{tabular}

The highest proportion of the respondents $(60.0 \%)$ were Asians, followed by Europeans, which represented 28 percent. This is an expected outcome since the study was conducted in an Asian country where Asian guests can easily access in any resorts in Bohol, Philippines because of its visa-free at the same time because of the beautiful tourist attractions. This result was supported by Setyowati\& Antariksa (2014) which said that there are many reasons why tourists want to visit in Asian country because of internal and external factors. The Philippines has many islands that can be visited, but people usually do tourism on the beach resorts because it has a lot of wonderful tourist attraction, recreational activities, and accommodation. 
Table 2: Level of Satisfaction of the Guests on the Housekeeping Standard Practices

\begin{tabular}{|c|c|c|}
\hline Indicators & Mean & Interpretation \\
\hline \multicolumn{3}{|l|}{ Housekeeping Services } \\
\hline Handling/dealing with the guests' housekeeping requests. & 3.60 & Very Satisfied \\
\hline Advising guests on room and housekeeping equipment. & 3.40 & Very Satisfied \\
\hline $\begin{array}{l}\text { Setting- up of equipment and trolleys required for servicing } \\
\text { rooms. }\end{array}$ & 3.60 & Very Satisfied \\
\hline Accessing rooms requiring services. & 3.44 & Very Satisfied \\
\hline Handling lost and found guest items. & 3.60 & Very Satisfied \\
\hline Cleaning and storing trolleys and equipment. & 3.56 & Very Satisfied \\
\hline Overall Mean & 3.53 & Very Satisfied \\
\hline \multicolumn{3}{|l|}{ Cleaning and Preparing Rooms } \\
\hline Making up of beddings. & 3.72 & Very Satisfied \\
\hline Removing and replacing bed linens. & 3.60 & Very Satisfied \\
\hline Cleaning and clearing rooms. & 3.60 & Very Satisfied \\
\hline Cleaning and checking furniture and fixtures. & 3.56 & Very Satisfied \\
\hline Checking and replenishing room supplies. & 3.44 & Very Satisfied \\
\hline Checking room for any defects and unusual occurrence. & 3.60 & Very Satisfied \\
\hline Overall Mean & 3.59 & Very Satisfied \\
\hline \multicolumn{3}{|l|}{ Customer Service } \\
\hline Greet customer. & 3.72 & Very Satisfied \\
\hline Identifying the needs of customers. & 3.56 & Very Satisfied \\
\hline Delivering service to the customer. & 3.64 & Very Satisfied \\
\hline $\begin{array}{l}\text { Handling queries through the use of standard business tools } \\
\text { and technology. }\end{array}$ & 3.40 & Very Satisfied \\
\hline $\begin{array}{l}\text { Handling complaints/ conflict situations, evaluation, and } \\
\text { recommendations. }\end{array}$ & 3.44 & Very Satisfied \\
\hline Overall Mean & 3.55 & Very Satisfied \\
\hline GRAND MEAN & 3.56 & $\begin{array}{l}\text { VERY } \\
\text { SATISFIED }\end{array}$ \\
\hline
\end{tabular}

In the aspect of housekeeping services of the resorts in Anda, Bohol. The data contained in table 2 reveals that the respondents were very satisfied, as indicated by the average mean of 3.53. The data imply that the room attendants' were very attentive in assisting and providing the housekeeping request of the guests. These findings were supported to the 2013 Cleaning Industry Insights Survey from P\&G Professional that the most critical business factor in keeping guests satisfaction is by providing the requests of the guests about housekeeping services and meet their expectations. Moreover, to deliver a great first impression of the resort, consider the cleanliness of the property as it aims to create a memorable experience that keeps guests coming back.

As with the cleaning and preparation of rooms, the respondents were also very satisfied as revealed by the average mean of 3.59. Specifically, the respondents were highly satisfied in the aspect of making up of beddings $(\mu=3.72)$. It means that the room attendants were knowledgeable and skillful enough in making up bed. Although the rating in terms of checking and replenishing room supplies indicated high satisfaction $(\mu=3.44)$ on the part of the resorts' guests, at a lesser extent compared to other sub-items. Since small-scale resorts had limited room supplies and the room attendants were not well-oriented in checking-up and refilling of supplies when the need arises.

Moreover, housekeeping supervisors showed fewer efforts in supervising and inspecting all assignments of the room attendants and other housekeeping staff to keep and maintain guests' facilities and guests' rooms in good order, clean and in a sanitary condition. These results were supported by Kelly (2018) which said that the housekeeping supervisors should supervise the room attendants and ensure that they perform based on the prescribed hotel housekeeping standards. Room attendants' duties include cleaning and turning down of beds and to make sure that the linens are fresh and clean, re-ordering rooms once guests leave, and make sure that the areas are dust free. Failure to ensure this duty leads to dissatisfaction. A resort housekeeping supervisors not only supervises room attendants in conducting their duties but also investigates any complaints guests make and takes corrective action. Furthermore, housekeeping supervisors see to it that resort guests have adequate supplies both within their hotel rooms and in the public areas that they visit, such as paper roll, shampoo, conditioner, soap, etc. Different categories of hotel rooms entitle guest to different supplies. 
In the area of customer service, the overall mean was 3.55, very satisfied. The resorts' guests were also delighted, especially in terms of welcoming and greeting the customers. This item obtained the highest mean of 3.72. It means that the guests were greeted well by the resort attendants during their stay in the resort and they manifested desirable actions in enabling the guests to feel unique, consequential, and sense of importance. This finding was upheld by Kimanuka (2014) which demonstrates that fantastic client administration makes clients feel that they care about building up a long haul relationship that implies something other than making a deal. Improving first contact goals is one of the essential drivers of consumer loyalty.

Nevertheless, although high satisfaction was also found in handling queries through the use of standard business tools and technology, it obtained the lowest mean of 3.40. It implies that housekeeping staff was not slanted on operating common business tools, technology in handling queries and other housekeeping equipment used in housekeeping services.

Table 3: Problems Encountered by the Guests about Housekeeping Standard Practices
\begin{tabular}{lcccc}
\hline Indicators & Frequency & Percentage & Rank \\
\hline Hair in the bath or on the floor. & 10 & 20.00 & 1 \\
Smelly and stained bed sheet. & 8 & 16.00 & 2 \\
Not enough toiletries (paper roll, shampoo, & 8 & 16.00 & 2 \\
conditioner, soap, etc.) & 8 & 16.00 & 2 \\
Some areas covered in dust. & 8 & 16.00 & 2 \\
Noise from neighboring rooms. & 6 & 12.00 & 3 \\
Fingerprints on windows and mirrors. & 6 & 12.00 & 3 \\
Housekeeping staff look unprofessional & 6 & 12.00 & 3 \\
(dressing unprofessionally) & 6 & 12.00 & 3 \\
Mosquitoes. & 4 & 8.00 & 4 \\
No hot water. & 2 & 4.00 & 5 \\
The bedding or towels have holes or rips. & & & 5 \\
There is no sign to hang on the door & & & \\
requesting a room to be cleaned. &
\end{tabular}

Table 3 showed that the respondents usually encounter the problems of having hairs in their bathrooms or on the floor with the highest rank among the 13 common problems encountered by the resort guests. It can be a real discomfort to clean up hairs in the bath or on the floors, but it is also a job of room attendants that forced to do regularly. In the bathroom, it can get complicated, it cannot use a vacuum, and most of the time brooms will use that do not work for sweeping up hair.

Furthermore, styling products can compound this issue, and even the flooring type can be an annoyance when you are trying to clean up hair. Surfaces like linoleum can build static and cause the pieces of hair to cling, and tile floors can cause strands to get stuck in the grout lines. Smelly and stained bed sheet, some areas covered in dust, and not enough toiletries was the second common problems encountered by the guests.

These problems are trying to find out that needs further attention by the room attendants and housekeeping supervisors who are responsible for doubling check the work of their attendants. These results were supported by Kovacs (2013) that the cleanliness of guest bathrooms, towels, linens and common areas all play an essential role in guest satisfaction. Thus, survey respondents from the hospitality industry also noted that the number one cause of worry about cleaning or disinfection overall is guest dissatisfaction or complaints.

Noise from neighboring rooms also ranked second on problems encountered by the guests. A well-known issues that hotel visitors experience is the point at which the neighbors in nearby rooms are uproarious, and this can go from overwhelming wheezing through to the individuals who are up late around evening time or coming back from a night out. The other circumstance which can likewise happen is the point at which the room is above or by the retreat's bar or capacity room, and the commotion from these spots also can be an issue. Eventually there will have two alternatives here, and addressing the inn staff to request another room is something that can be effective, especially prior around evening time when not all rooms might be taken. Then again, numerous visitors will as of now have commotion counteracting earphones or earplugs to suffocate the clamor, with the earplugs intended for the individuals who lay down with substantial snorers being especially valuable. 
Table 4: Results on the Test of Significant Relationship between the Guests' Profile and the Problems Encountered

\begin{tabular}{cccll}
\hline \multicolumn{1}{c}{ Variable } & $\begin{array}{c}\text { Spearman's } \\
\text { rho }\end{array}$ & $\begin{array}{c}\text { Critical } \\
\text { Value }\end{array}$ & Significance & $\begin{array}{l}\text { Decision on } \\
\text { Ho }\end{array}$ \\
\hline $\begin{array}{l}\text { Problems Encountered } \\
\text { and }\end{array}$ & -0.0337 & 0.279 & $\begin{array}{l}\text { No Significant } \\
\text { Relationship }\end{array}$ & $\begin{array}{l}\text { Failed to Reject } \\
\text { Ho }\end{array}$ \\
Age & 0.1298 & 0.279 & $\begin{array}{l}\text { No Significant } \\
\text { Relationship }\end{array}$ & $\begin{array}{l}\text { Failed to Reject } \\
\text { Ho }\end{array}$ \\
Gender & 0.0000 & 0.279 & $\begin{array}{l}\text { No Significant } \\
\text { Relationship } \\
\text { No Significant } \\
\text { Relationship }\end{array}$ & $\begin{array}{l}\text { Failed to Reject } \\
\text { Ho }\end{array}$ \\
$\begin{array}{l}\text { Failed to Reject } \\
\text { Ho }\end{array}$ \\
Origin
\end{tabular}

With the Spearman's Rho of -0.0337 which is lower than the critical value $(0.279)$, this means that there is no significant relationship between age and the respondents' perception on the problems encountered during their stay in the resort.

It implies that the age of the respondents does not relate to how they make the perception of the problems they experienced as resorts' guests.

There is also no significant relationship between the gender and resorts' guests idea on problems met as customers, based on Spearman's rho value of 0.1298, which is lower than the critical value of 0.279. It indicates that the gender of the respondents does not influence their perception of the problems they had encountered as guests of the resorts. Therefore, the hypothesis is at this moment accepted.

Moreover, there is also no significant relationship between the civil status of the respondents and their insights on the problems encountered while staying at the resort, as revealed by Spearman's Rho value of 0.0000 , and is lower than the critical value of 0.279 . This means that whether the respondents are single, married, separated or widowed, it does not have any bearing on their perception on the problems as resorts' guests.

Lastly, there is no significant relationship between the continent of origin and respondents' view on the problems encountered during their stay in the resorts of Anda, Bohol, as revealed Spearman's rho value of -0.2503 , lower than the critical value of 0.279 .

\section{Conclusions}

Resort guests had expressed their satisfaction with the overall service that they received, especially in housekeeping services, cleaning and preparing rooms, and customer service. However, resort guests also encountered some problems while staying in the resort based on the services rendered by the resort attendants. The information on service quality gaps could help resort managers to diagnose where performance improvement can best be targeted. To achieve quality service, establishments need a relatively stable labor force to allow internalization of service standards. Thus, room attendants' low performance will negatively impact the quality of service and the desired competitiveness of an establishment.

\section{References}

Batinić, I. (2015). Organization of business in hotel housekeeping. Vocational School, Vukovar, Croatia. Unpublished Master's Thesis. Retrieved from https://goo.gl/nErtWa.

Bitran, G., \&Pedrosa, L. (1998). A structured product development perspective for service operations. European Management Journal, Volume 16, Issue 2, Pages 169-189. Retrieved on April 1998, from https://bit.ly/2TioRzn.

Carev, D. (2008). Guest satisfaction and guest loyalty study for hotel industry. Rochester Institute of Technology. Unpublished Master's Thesis. Retrieved from https://goo.gl/NLJfuH.

Cleaning Industry Insights Survey Fact Sheet. (2013). P\&G Professional's. Retrieved from https://bit.ly/2Lidbfy.

Davis, C. (2014). The importance of professional standards. Wolters Kluwer. Volume12-issue5- p4/doi: 10.1097/01.NME.0000452691.04516.96.

Dorling, S. (2017). Customer service theory. Hearts Newspapers. Retrieved on January 8, 2018, from https://goo.gl/KB9egp. 
Fouad, M. A., Hussein, S., \&Attia, A. Y. (2013). Housekeeping performance and guest satisfaction in resort hotels. International Journal of Heritage, Tourism, and Hospitality, Volume (7), No. (2). Retrieved from https://bit.ly/2sUSk73.

Hodson, M. (2017). The five most common problems for hotel guests and how to deal with them. Tripsavvy. Retrieved on January 28, 2018, from https://goo.gl/efNKgU.

Kelly, B. (2018). The role of a manager in housekeeping in the hotel industry. Hearst Newspapers. Retrieved on January 1, 2018, from https://goo.gl/fLjtq7.

Kimanuka, O. (2014). Why customer service in hospitality industry is everything. The News Time. Retrieved on December 12, 2014, from https://goo.gl/kVJx2H.

Knezevic, M., Cerovic, S., Dzamic, D., \&Radojevic, T. (2017). Total quality management implementation and guest satisfaction in hospitality. Central and Eastern European Online Library. Retrieved from https://bit.ly/2Wts8hv.

Kovacs, S. (2013). Creating a great first impression in your hotel through cleanliness. P\&G Pro Line Information. Retrieved on November 5, 2013, from https://goo.gl/Gq6guV.

Pesonen, J. (2015). Internal housekeeping versus outsourced housekeeping. Saimaa University of Applied Sciences. Unpublished Master's Thesis. Retrieved from https://goo.gl/R6T518.

Phillips, C. (2017). The roles and responsibilities of the housekeeping department. Career Trend. Retrieved on July 5, 2017, from https://goo.gl/B84LSe.

Pongsiri, K., Suksutdhi T., \&Kanchanapairod, C. (2013). Housekeeping, human resources: Competency service standard management for hotel business in ASEAN. International College, SuanSunandhaRajabhat University. Retrieved from https://goo.gl/QSvynD.

Setyowati, R. D. E., \&Antariksa, S. K. S. (2014). Influence tourism motives, the tourism component of the interest of foreign tourists visiting the beach in Indonesia. International Foundation for Research and Development (IFRD), 80. Retrieved from https://bit.ly/2sUSk73.

The Travel \& Tourism Competitiveness Report (2017). World Economic Forum. Retrieved on April 5, 2017, from https://bit.ly/2o5O4zU.

Tsang, N., \&Qu, H. (2000). Service quality in China's hotel industry: A perspective from tourists and hotel managers. Research Gate. Retrieved on September 10, 2017, from https://bit.ly/2JuEvC1.

Yuksel, A. (2008). Dissonance theory. Research Gate. Retrieved on January 4, 2018, from https://bit.ly/2Lcz7st.

Živković, M. (2011). Customer satisfaction in business: A case study of Moon Travel LTD, Finland. Laurea University of Applied Sciences. Retrieved from https://bit.ly/2mrRn32. 